International Journal of Agricultural Policy and Research Vol.10 (1), pp. 26-30, January 2022

Available online at https://www.journalissues.org/IJAPR/

https://doi.org/10.15739/IJAPR.22.004

Copyright (C) 2022 Author(s) retain the copyright of this article

ISSN 2350-1561

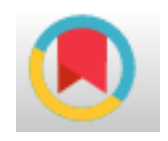

\title{
Effects of different drying methods and packaging materials on the physical and sensory qualities of tomato (Lycopersicon lycopersicum L.)
}

\author{
Ahmad, $A^{1 *}$., Gungula, D. $T^{2}$., \\ Tame, V.T²., Kapsiya, J1., \\ Ilesanmi, J.03., \\ and \\ Kirawa, D. M. A4. \\ ${ }^{1}$ Horticultural Department, Federal \\ College of Horticulture, Dadin Kowa, \\ Gombe State, Nigeria \\ 2Department of Crop Production and \\ Horticulture, Modibbo Adama \\ University of Technology, Yola, \\ Adamawa State, Nigeria \\ ${ }^{3}$ Department of Food Science and \\ Technology, Modibbo Adama \\ University of Technology, Yola, \\ Adamawa State, Nigeria \\ ${ }^{4}$ No. 169, Hawul Close, Pompomari \\ Estate, Maiduguri, Nigeria \\ *Corresponding Author Email: \\ abubakarahmad598@gmail.com
}

Tel.: +2348061559188
Fresh tomato fruits have a very limited shelf life partly due to their high moisture content and respiration rate. A possible way of storing tomato fruits is to dry and process them into powder or paste. Therefore, this research was conducted to determine the effects of drying methods and packaging materials on physical and sensory qualities of powdered tomato in Yola, Adamawa State, Nigeria. Harvested fruits of tomato variety, "Rio de grande" were subjected to blanching and subsequent drying methods and packaging materials. The experiment was laid out in a Completely Randomized Design (CRD); with the drying methods placed in main plot while the packaging materials in sub-plot and repeated three times before storage for twelve weeks. At four weeks of storage, oven drying method was found to be statistically different $(p \leq 0.05)$ in terms of water absorption capacity value of $3.19(\mathrm{mg} / \mathrm{100g})$. The glass jars performed better than polythene bags in color retention, taste and consistency at four weeks of storage. The study shows that tomato fruits can be successfully dried using oven, sun and shade drying methods but preferably oven drying method. The processed powder could be successfully stored for 12 weeks or above using either glass jars or plastic container without affecting the consumer appeal and this will also reduce the postharvest losses of tomato fruits.

Keywords: Tomato, drying, packaging, physical properties, sensory quality

\section{INTRODUCTION}

Tomato (Lycopersicon lycopersicum L.) meaning "worlfpeach", is a herbaceous, usually sprawling plant of the Solanaceae or night shade family that is typically cultivated for the purpose of harvesting it's fruits for human consumption (Agrios, 2005). Tomato is one of the most important commercial and dietary vegetable crops that are cultivated all over the world for its fleshy fruits. Tomato being a climacteric fruit, rapid rise in rate of respiration leads to fruit deterioration during handling. After harvesting further transpiration loses make the fruit shrive and eventually becoming unmarketable (Adaskaveg, 2002). They are eaten fresh in salads or processed and can be stewed, fried, baked and used to produce soup, or used as juice (Varela et al., 2003).

In addition to this versatility, tomatoes are also an important source of vitamins and minerals. According to 
Keith (1999), antioxidants can prevent, stop, or reduce oxidative damage. Antioxidants are naturally occurring chemicals in many foods, especially fruits and vegetables. Foods rich in antioxidants help protect humans from disease attack and they slow the aging process (Sun et al., 2009). The balance between free radicals and antioxidants will determine the amount of oxidative stress a person is undergoing. Decreasing free radical production, increasing dietary antioxidant intake or both can reduce oxidative stress (Keith, 1999). Lycopene is the pigment responsible for the characteristic deep red color of ripe tomatoes and their products (Ibitoye et al., 2009). According to Lindshield et al., (2006) lycopene has earned a plethora of interest for its use as a preventative measure and possible treatment for cardiovascular disease, skin health, eye health, and prostate cancer. These positive effects on human health are attributed in large part to the antioxidant compounds found in high quantities in fruits and vegetables (Ames, 1993). Tomato may be preserved into paste and powders which is used for cooking and in production of fruit drinks, puree and ketchup (Ayandiji and Adeniyi, 2011).

Tomato has a very short shelf life because of its climacteric nature, high moisture content and high respiration rate which predisposes it to loss of wholesomeness. Also very high percentage of tomato suffers a lot of bruises and cracks because of its thin epidermis during harvesting which affect quality and subsequent market value. Drying is a mass transfer process that consists of water moisture evaporation from foodstuffs (Ayandiji and Adeniyi, 2011). The initial moisture content of the product influences the drying rate (Alamu et al., 2010). During drying, the moisture contained in the product is vaporized under the effect of heat and transferred to the ambient air (Alamu et al., 2010). Drying is an excellent way to preserve food and solar dryers are appropriate food preservation technology for sustainable development. Drying was probably the first ever food preserving method used by man, even before cooking (Alamu et al., 2010). It involves the removal of moisture from agricultural produce so as to provide a product that can be safely stored for longer period of time. In view of these, this study was carried out in Yola with the objective to determine the effects of drying methods and packaging materials on the physical and sensory qualities of powdered tomato.

\section{MATERIALS AND METHODS}

The study was carried out in the laboratories of the Departments of Crop Production and Horticulture, and Food Science and Technology, Modibbo Adama University, Yola Adamawa State, Nigeria.

\section{Sample Collection}

Tomato fruits at a fully matured ripe stage were harvested from a farm at Dumne, Song Local Government Area of Adamawa State. Fruits of almost uniform colors, undamaged, free from physical infection and bruises were selected for the experimental purpose.

\section{Experimental Design and Drying Procedures}

The treatments were laid out in a Randomized CompleteDesign (CRD) with drying methods (oven drying, sun drying and shade) placed in the main plot while the packaging materials (glass jar, plastic container and polythene) were placed in the sub-plot and repeated three times. The selected tomato fruits were dipped in boiling water for $5 \mathrm{~min}$ and plunged into cold water (blanching) to deactivate microbial activity on the surface of the fruits and retain its color after drying. The fruits were sliced into uniform sizes so as to maintain uniform drying until constant weight was achieved. After drying, the dried products were ground into powder.

\section{Physical Analysis}

The bulk density was determined by using $10 \mathrm{~g}$ of sample weighed in $25 \mathrm{~cm}^{3}$ graduated measuring cylinder and was firmly tapped 30 times on a bench top to settle the sample volume. The water absorption capacity was determined as described by Onwuga (2005). $2 \mathrm{~g}$ of dried sample was mixed thoroughly with $20 \mathrm{~mL}$ of distilled water in a Kenwood blender for $30 \mathrm{~s}$. The mixtures were allowed to settle for $30 \mathrm{~min}$ at room temperature and then centrifuged. The volume of free water was decanted and discarded. The weight of water absorbed by $2 \mathrm{~g}$ of samples was calculated and expressed as water absorption capacity. It was expressed as grams of water absorbed per $100 \mathrm{~g}$ of sample.

\section{Sensory Evaluation}

Stews were prepared from different samples of dried samples. The color, consistency, taste, aroma and overall acceptability of each product were evaluated by 10 member panel that is familiar with the product. Each attribute was evaluated separately using 9.0 hedonic scales as described by Iwe (2002).

\section{Data Analysis}

The data obtained from the study were subjected to statistical analysis of variance (ANOVA). Means that were significantly different at ( $p \leq 0.05)$ were separated using Least Significant Difference (LSD).

\section{RESULTS}

The results of the effects of drying methods and packaging materials on physical and sensory qualities at four and twelve weeks after storage are presented in Tables 1 and 
Table 1. Effects of Drying Methods and Packaging Materials on Physical Characteristics and Sensory Quality of Tomato Fruit Powder at Four Weeks of Storage

\begin{tabular}{|c|c|c|c|c|c|c|c|}
\hline Treatments & $\begin{array}{c}\mathrm{H}_{2} \mathrm{O} \text { Absorption } \\
(\mathrm{mg} / \mathrm{100 \textrm {g }})\end{array}$ & $\begin{array}{c}\text { Bulk Density } \\
\text { (mg/100g) }\end{array}$ & Colour & Taste & Aroma & Consistency & $\begin{array}{c}\text { Overall } \\
\text { Acceptability }\end{array}$ \\
\hline \multicolumn{8}{|l|}{ Drying Methods } \\
\hline Shade & $2.94 \pm 0.24$ & $0.60 \pm 0.01$ & $7.33 \pm 0.50$ & $6.67 \pm 0.50$ & $7.78 \pm 0.66$ & $7.11 \pm 0.60$ & $7.33 \pm 0.50$ \\
\hline Sun & $2.88 \pm 0.28$ & $0.61 \pm 0.01$ & $7.57 \pm 0.73$ & $6.67 \pm 0.44$ & $7.89 \pm 0.33$ & $7.33 \pm 0.50$ & $7.56 \pm 0.50$ \\
\hline Oven & $3.19 \pm 0.20$ & $0.62 \pm 0.01$ & $7.57 \pm 0.53$ & $7.11 \pm 0.60$ & $7.78 \pm 0.44$ & $7.11 \pm 0.50$ & $7.67 \pm 0.53$ \\
\hline $\mathrm{P}<\mathrm{F}$ & 0.003 & 0.132 & 0.309 & 0.166 & 0.790 & 0.111 & 0.284 \\
\hline LSD & 0.195 & 0.016 & 0.398 & 0.591 & 0.504 & 0.252 & 0.504 \\
\hline \multicolumn{8}{|c|}{ Packaging Materials } \\
\hline Polythene Bag & $3.02 \pm 0.23$ & $0.61 \pm 0.01$ & $7.00 \pm 0.50$ & $7.00 \pm 0.60$ & $7.00 \pm 0.44$ & $7.44 \pm 0.53$ & $7.78 \pm 0.53$ \\
\hline Plastic Container & $3.02 \pm 0.24$ & $0.61 \pm 0.01$ & $7.57 \pm 0.53$ & $6.44 \pm 0.44$ & $7.57 \pm 0.88$ & $6.89 \pm 0.33$ & $8.00 \pm 0.44$ \\
\hline Glass Jar & $2.97 \pm 0.35$ & $0.61 \pm 0.01$ & $7.89 \pm 0.33$ & $7.00 \pm 0.44$ & $7.89 \pm 0.50$ & $7.44 \pm 0.53$ & $7.67 \pm 0.54$ \\
\hline $\mathrm{P}<\mathrm{F}$ & 0.778 & 0.066 & 0.008 & 0.003 & 0.251 & 0.034 & 0.890 \\
\hline LSD & 0.195 & 0.004 & 0.504 & 0.313 & 0.419 & 0.464 & 0.576 \\
\hline
\end{tabular}

Table 2. Effects of Drying Methods and Packaging Materials on Physical Characteristics and Sensory Quality of Tomato Fruit Powder at Twelve Weeks of Storage

\begin{tabular}{|c|c|c|c|c|c|c|c|}
\hline Treatments & $\begin{array}{c}\mathrm{H}_{2} \mathrm{O} \text { Absorption } \\
(\mathrm{mg} / \mathrm{100g})\end{array}$ & $\begin{array}{c}\text { Bulk Density } \\
\text { (mg/100g) }\end{array}$ & Colour & Taste & Aroma & Consistency & $\begin{array}{c}\text { Overall } \\
\text { Acceptability }\end{array}$ \\
\hline \multicolumn{8}{|l|}{ Drying Methods } \\
\hline Shade & $2.43 \pm 0.22$ & $0.61 \pm 0.24$ & $7.22 \pm 0.44$ & $6.89 \pm 0.33$ & $6.22 \pm 0.44$ & $6.56 \pm 0.53$ & $7.33 \pm 0.50$ \\
\hline Sun & $2.26 \pm 0.23$ & $0.61 \pm 0.28$ & $7.22 \pm 0.44$ & $7.00 \pm 0.50$ & $7.11 \pm 0.33$ & $7.22 \pm 0.44$ & $7.44 \pm 0.53$ \\
\hline Oven & $2.23 \pm 0.35$ & $0.61 \pm 0.19$ & $7.22 \pm 0.44$ & $7.00 \pm 0.00$ & $7.22 \pm 0.67$ & $7.22 \pm 0.44$ & $7.44 \pm 0.53$ \\
\hline $\mathrm{P}<\mathrm{F}$ & 0.338 & 0.321 & 1.000 & 0.694 & 0.010 & 0.040 & 0.790 \\
\hline LSD & 0.391 & 0.003 & 0.436 & 0.398 & 0.504 & 0.534 & 0.504 \\
\hline \multicolumn{8}{|c|}{ Packaging Materials } \\
\hline Polythene Bag & $2.30 \pm 0.35$ & $0.61 \pm 0.23$ & $7.00 \pm 0.00$ & $7.00 \pm 0.00$ & $7.00 \pm 0.87$ & $6.89 \pm 0.33$ & $7.44 \pm 0.53$ \\
\hline Plastic Container & $2.32 \pm 0.35$ & $0.61 \pm 0.24$ & $7.67 \pm 0.50$ & $7.11 \pm 0.33$ & $7.67 \pm 0.50$ & $7.79 \pm 0.44$ & $7.33 \pm 0.50$ \\
\hline Glass Jar & $2.30 \pm 0.08$ & $0.61 \pm 0.35$ & $7.00 \pm 0.44$ & $6.78 \pm 0.44$ & $7.00 \pm 0.53$ & $7.33 \pm 0.71$ & $7.44 \pm 0.53$ \\
\hline $\mathrm{P}<\mathrm{F}$ & 0.959 & 0.107 & 0.001 & 0.100 & 0.022 & 0.032 & 0.859 \\
\hline LSD & 0.193 & 0.005 & 0.342 & 0.313 & 0.342 & 0.419 & 0.504 \\
\hline
\end{tabular}

2 , respectively. Water absorption capacity indicated highly significant differences $(\mathrm{p} \leq 0.05)$ among the drying methods at 4 weeks of storage but there was no significant difference ( $>0.05)$ at 12 weeks of storage. At four weeks of storage, the highest water absorption capacity was obtained from oven dried tomato $(3.19 \mathrm{mg} / 100 \mathrm{~g}$ ) followed by shade dried $(2.94 \mathrm{mg} / 100 \mathrm{~g})$ while sun dried was found to be least (2.88 $\mathrm{mg} / 100 \mathrm{~g}$ ). At both four and twelve weeks of storage, there was no significant difference ( $p>0.05$ ) among the packaging materials used. The drying methods were not significantly different $(p>0.05)$ at four and twelve weeks of storage in terms of bulk density. Likewise at both four and twelve weeks of storage, there were no significant difference $(p>0.05)$ in bulk density among the packaging materials used.

The different drying methods were found to be not significantly different $(p>0.05)$ in color at both four and twelve of storage but there was highly significant differences $(\mathrm{p} \leq 0.05)$ among the packaging materials used both at four and twelve weeks of storage. At four weeks of storage, glass jar had the highest mean value of 7.89 but was not statistically difference $(\mathrm{p} \leq 0.05)$ from plastic container, while the least mean value of 7.00 was obtained from polythene bag. At twelve weeks of storage, plastic container had the highest of 7.67 and it was statistically better than both glass jar and polythene bag with equal value of 7.00. The drying methods were not significantly different $(p>0.05)$ in taste at both four and twelve weeks of storage. However, there was significant difference $(p \leq 0.05)$ among the packaging materials used at four weeks of storage but no significant difference $(p>0.05)$ in taste were observed at twelve weeks of storage. At four weeks of storage, glass jar and polythene bag storage recorded the highest equal mean values of 7.00 while plastic container storage had the least mean value of 6.44.

The drying methods were not significantly different ( $p>0.05)$ in aroma at four weeks of storage, but there was significant difference $(p \leq 0.05)$ at twelve weeks of storage. At twelve weeks of storage, oven dried method recorded the highest mean of 7.22 and this was not statistically different from sun dried method which had 7.11, the lowest mean value of 6.22 was obtained from shade dried sample. There was no significant difference $(p>0.05)$ among the packaging materials used in terms of aroma at four weeks of storage, but there was significant differences $(p \leq 0.05)$ recorded among the packaging materials in aroma at 
twelve weeks of storage. At twelve weeks of storage, plastic container and polythene bag recorded the highest mean values of 7.00 , while the least mean value of 6.56 was obtained from glass jar. The drying methods were not statistically different ( $p>0.05)$ in consistency at four weeks of storage, but they was significantly different $(p \leq 0.05)$ at twelve weeks of storage. Oven dried and sun dried samples recorded the highest equal mean values of 7.22 while the least mean value of 6.56 was obtained from shade dried sample. There was significant difference $(p \leq 0.05)$ among the packaging materials used in terms of consistency at both four and twelve weeks of storage. At four weeks of storage, glass jar and polythene bag recorded the highest equal mean values of 7.44 while the least mean of 6.89 was obtained from plastic container. At twelve weeks of storage, plastic container recorded the highest mean value of consistency, followed by glass jar while the polythene bag had the least mean value of 6.79 .

Both the drying methods and the packaging materials were not significantly different $(p>0.05)$ in the overall acceptability of powdered tomato at both four and twelve weeks of storage.

\section{DISCUSSION}

This study revealed that drying methods and packaging materials performed differently when they were assessed under different parameters at different storage time. Water absorption capacity of the processed tomato fruits was high when compared to other flours. The highest values of water absorption capacity recorded from the sample that were dried using the oven is an indication that the samples may be more cohesive when processed (Ogundele et al., 2019). The higher water absorption capacity from the powdered tomato that was obtained from the oven drying method could be due to the higher and consistent temperature produced by the oven as compared to the other methods of drying which gave rise to faster rate of drying. This might have been the reason for more hydrophilic tendency in dried products with the oven than the other methods at four weeks of storage. As the storage period progressed to 12 weeks, this property of higher water absorption capacity from oven dried samples was lost. This is an indication that prolonged storage can lead to the loss in some properties of the tomato fruit powder. Therefore, at 12 weeks after storage, there were no significant differences among the different drying methods even where different packaging materials were used to package the products. The results show that where available, the use of oven drying could be preferred over sun drying and shade drying because oven drying will give rise to higher drying efficiency than the other methods of drying. Higher drying efficiency will result in higher reduction in moisture content which will lead to higher water absorption capacity during the subsequent use of the products. This finding is in agreement with the findings of Ogundele et al. (2019) who reported higher water absorption capacity with increased oven drying temperature. According to Emperatriz et al. (2008) and Ogundele et al. (2019) high reduction of moisture during drying lead to high water absorption capacity and also decreases the perishability of the products and extend shelf life, thereby making the products available almost all year round. The higher ability of oven drying method to efficiently remove moisture was earlier observed by Damirel and Turhan (2003) who worked on dwarf canvedish and banana. They concluded that oven drying ensures higher rate of water absorption capacity.

The non-significant difference observed among the different drying methods and packaging materials in bulk density both at both four and twelve weeks of storage is an indication that the particle size of the dried tomato fruit powder was not affected by the drying methods, packaging materials and the storage time used. The tomato fruits were dry sufficiently enough to be ground to very fine particle size. According to Mephba et al. (2007), low bulk density is an indication of the potentiality of the product in the formulation of complementary food where high nutrients are needed. Bulk density generally depends on starch, protein content and particle size. Generally, the bulk density was low in all the samples and the non-significant differences among the drying methods and packaging materials is an indication that the volume of the produce will not decrease during storage, handling and distribution as reported by Ogunlakin et al. (2012). The non-significant differences among the drying methods in sensory attributes at four weeks of storage and 12 weeks of storage (except for aroma and consistency at 12 weeks of storage) is an indication that the different drying methods will give consumers acceptable products as the consumers had no clear cut choice from the three drying methods. With increased storage period to 12 weeks, the consumers had more preference for products dried in oven and least preference for those dried in shade. This might be due to the faster drying in the over which prevented biochemical reaction in the produce before complete drying which could affect aroma. The least preference for shade drying could be due to the slower drying in the shade which predisposes the produce to chemical reactions and growth of fungi. Consistency is largely affected by the efficiency of drying which can be better achieved in the oven than in the shade. This might have been the cause of the less preference for the consistency of products under shade drying.

The higher preference of consumers for powdered tomato packaged in glass jar for most of the parameters measured at four weeks of storage could be due to the air tight nature of the glass jar and the ease of packaging the powder in glass jar. Marsh and Bugusu (2007) reported that glass jar was preferred for storage of products of this nature because it has a static chemical property and low permeability to absorb moisture from the storage environment which ensures unimpaired taste, color, and other vital nutrients. With prolonged storage period, most consumers had more preference for products that were packed with plastic container indicating that plastic 
containers are good substitute for glass jars. The nonsignificant difference observed in the rating of the dried products with different drying methods and packaging materials for their overall acceptability both at four and twelve weeks of storage could be attributed to the pretreatment (blanching) of tomato fruits prior to drying and subsequent packaging before storage.

\section{Conclusion}

In this study, the various drying methods and packaging materials used were capable of preserving the physical and sensory qualities in the dried samples of tomato without total loss of these parameters. Shade dried and oven dried samples were found to retain most of the physical and sensory qualities of powder tomato after storage. Oven and sun drying were faster than the shade drying method. Oven drying was more cost effective and gave the lowest moisture content in this study, proving lower moisture content and higher nutritive values, thus confers a greater increase in shelf-life on the dried samples and other sensory qualities. On the other hand, glass jar performed better than polythene bags in color, taste and consistency at four weeks of storage and was however not statistically different $(p>0.05)$ from plastic containers in some cases in these traits at the same storage period.

\section{Acknowledgements}

I want to acknowledge with sincere gratitude the supervision and guidance given to me by two sagacious and scholarly supervisors; Professor D. T. Gungula and Dr. V. T. Tame, their commitment in every aspect of the work starting from the conception to the completion of this study encourage me. I am also grateful to Dr. J. Kapsiya and Mr. D.M. K. Kirawa from the Department of Horticultural Technology and Pompomari Estate, Maiduguri, Nigeria respectively for their technical inputs and generosity and also Dr. J. O. Ilesanmi and Mrs F. U. Muhammad for their endless help with physical and sensory analysis.

\section{Conflict of interests}

The authors declare that they have no conflicting interests

\section{REFERENCES}

Adaskaveg JE, Forster H, Sommer NF, (2002). Principles of post-harvest pathology and management of decays of edible horticultural crops. P.196-197.

Agrios GN (2005). Plant Pathology, $5^{\text {th }}$ Edition, Academic Press, New York, USA. P: 58

Alamu OJ, Nwaokocha, CN and Adunola O (2010). Design and construction of a domestic passive solar food dryer, Leonardo J. Sci. p. 71-82.
Ames BM, Shigena MK, Hagen TM (1993). Oxidants, antioxidants and the degenerative diseases of ageing. J. Health National academic Science. 7915-7922.

Ayandiji AOR, Adeniyi OD (2011). Determinant postharvest losses among tomato farmers in Imeko-Afon Local Government Area of Ogun State, Nigeria. Global J. Sci. Frontier Res., 11(5): 22-28.

Demirel D, Turhan M (2003). Air drying behavior of dwarf cavendish and gross michel banana slices. J. Food Engineering. 59: 1-11.

Emperatriz PD, Ronald M, Elevina P, Mily S (2008). Production and characterization of unripe plantain (Musa paradisiacal L.). Flours: Intercienca, 33:290-296.

Ibitoye DO, Akin-Idowu PE, Ademoyegu OT (2009). Agronomic and lycopene evaluation in tomato (Lycopersicon lycopersicum Mill.) as a function of genotype. World Journal of Agricultural Sciences 5(5):892-895.

Iwe MO (2002). Handbook of sensory method and analysis. Rejoint Comm. Ervices ltd, Uwani EnuguPp: 11-13.

Keith RE (1999). Antioxidants and Health. Pp: 1-4. Pub: Alabama Cooperative Extension System Pub ID: HE-0778

Lindshield BL, Canene-Adams K, Erdman JW Jr. (2006). Lycopenoids: Are lycopene metabolites bioactive? Arch. Biochemistry and Biophysics. 458(2):136-140. Pub: Elsevier Inc.

Marsh K, Bugusu B (2007). Food packaging? Roles, materials, and environmental issues. J. Food Sci.72(3):3955.

Mephba HD, Eboh L, Nwaojigwa SU (2007). Chemical composition, functional and baking properties of wheat plantain composite flours. African J. Food and Agricultural Nutrition.7(1): 22.

Ogundele OD, Thompson SO, Lawalsonsimisola K, Demehin BF (2019). Effects of drying temperature on proximate composition and functional properties of (Colocasiaesculenta) cocoyam flour. International Journal of Recent Innovation in Food Science and Nutrition. Vol. 2 , Issue 1.

Ogunlakin GO, Oke MO, Babarinde GO, Olatunbosun DG (2012). Effect of drying method on proximate composition and physic-chemical properties of cocoyam flour. American J. Food Technol. Academic J. Inc. 7(4): 245-250.

Onwuga GI (2005). Food Analysis and instrumentation, theory and practice. Nepthali Prints. Pp. 111.

Sun T, Simon PW, Tanumihardjo SA (2009). Antioxidants and antioxidant capacity of biofortified Carrots (Daucus carota, L.) of various colors USDA Journal of Agricultural and Food Chemistry. 57(10):4142-4147.

Varela AM, Seif A, Lohr B (2003). A guide to IPM in tomato production in tomato production in Eastern and Southern Africa. 
